\title{
Development and main research status of tracked vehicle suspension system
}

\author{
Guoying Xu, Dabing Xue , Xinming Yao, andTao Wang \\ Academy of Armored Force Engineering, Beijing 100072; \\ 1660137831@qq.com
}

\begin{abstract}
This paper briefly introduces the development history of the suspension, based on the existing literature, from the two aspects of the development of the elastic element, the shock absorber to introduce the history and development of suspension system. Combined with the research status at home and abroad to understand the latest trends in research of suspension system.The main problem facing the final suspension system and the development direction is put forward.
\end{abstract}

Keywords: Tracked vehicle, suspension system, research status, development trend.

\section{Introduction}

Since the birth of tracked vehicles, it has been more than 200 years of history. At first, the track was mainly used in agriculture. Until the beginning of the last century, the emergence of tanks and armored vehicles during the first World War led to the application of tracks to the military field. It has attracted wide attention from all countries. The Second World War, known as the "king of the Marines" tanks become an important weapon of victory in the battle to win the battle. Using a large number of tracked armored vehicle has had a significant impact on the process and results of wars. Compared to the wheeled vehicle, tracked vehicle has good cross-country mobility and performance. With the improving requirements and development of technology, high mobility has become an important goal of modern tracked vehicle design. In order to adapt to the future war, all countries put forward higher requirements to combat vehicle mobility, to get through the tactical initiative to flexibility. Motor performance index is mainly reflected in the average velocity and maximum velocity on the road.

For tracked armored vehicles, maneuverability also directly affects the firing accuracy of the artillery when moving. In the "2010 joint operation plan", the United States described two important properties of combat vehicle "firepower" and "mobility", also tend to focus on "mobility" on the one hand, even the idea of future MBT maximum speed should reach more than $100 \mathrm{~km} / \mathrm{h}$, the average speed of cross-country reached more than $55 \mathrm{~km} / \mathrm{h}$. The U.S. shows the importance of the mobility of tracked vehicles ${ }^{[1]}$. The world advanced tank has reached a higher level, such as the German Leopard 2A7+ tanks and Japanese type TK10 main battle tank, the cross-country average speed reached $55 \mathrm{~km} / \mathrm{h}$. The French Leclair MBT cross-country average speed of $50 \mathrm{~km} / \mathrm{h}$ and a new generation of Russian MBT 
maximum road speed of more than $85 \mathrm{~km} / \mathrm{h}$, the Belarus $2 \mathrm{~T}$ tank cross-country average the rate of $60 \mathrm{~km} / \mathrm{h}$, the maximum road speed reached $95 \mathrm{~km} / \mathrm{h}^{[2]}$.

As one of the most typical characteristics of tracked armored vehicle, crawler technology can be seen as a breakthrough in the development of wheel technology(see figure 1).

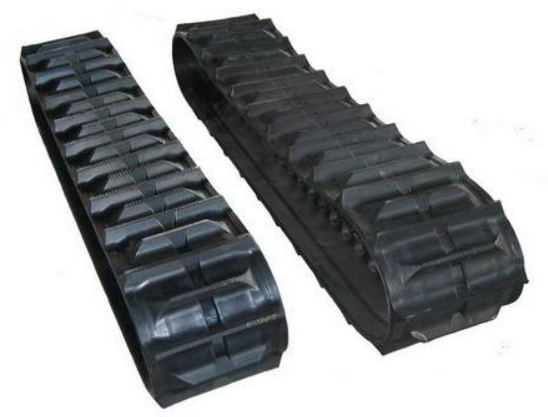

Figure. 1 track

People often call for crawler tank "own road".It can provide a way for the infinite wheel, it will not appear as wheeled vehicles through goukan wheels into a ditch in May the situation. The use of the track can make the contact area between the vehicle and the ground more large, and the lower ground pressure and the greater adhesion force can be ensured to ensure better passing of the vehicle on the relatively bad road surface. The tracked vehicle system allows the vehicle to travel smoothly on various off-road surfaces at a high speed, and can overcome a variety of natural and man-made obstacles ${ }^{[3]}$. The traditional method to improve the vehicle performance is a power device with high power, but the test showed that only through the suspension device to increase the engine power than without optimization of the tracked vehicle, to improve vehicle off-road average speed and not much help. When the tracked vehicle on the road at high speed, if the suspension performance is poor, will produce turbulence and large vibration, and to reduce the speed, even if a large power engine, can make full use of it, can only meet the occupant in normal operating conditions at a comfortable speed, thus reducing the important battle the performance of the tank the maximum speed of play, but also reduces the average driving speed. Suspension device with good performance, not only can improve the hit rate of moving shooting accuracy and first round, but also reduce the vibration acceleration of the passenger capacityand improve occupant comfort members work ${ }^{[4]}$.

\section{Development of suspension systems}

Tracked vehicle is a complex system consisting of many subsystems. Suspension is one of the most important subsystems in Tracked Vehicles. The structure of the suspension system is shown in the figure 2 . 


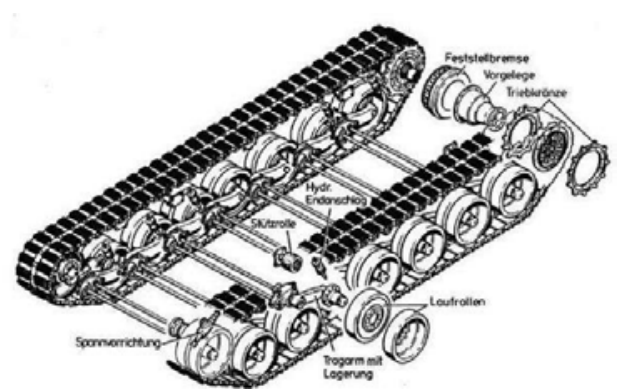

Fig. 2 suspension structure of tracked vehicle

\subsection{Development of elastic components.}

Suspension device of tracked vehicle is composed of the following parts, elastic components, shock absorber, limiting element, guide mechanism and other auxiliary parts. The elastic components and shock absorber are the most important parts, great structural parameters influence on the vibration characteristics of the suspension system.

For elastic components, they can be divided into classical spring type, torsion bar type and liquid air type. The classical spring type includes plate spring, cylindrical spring, volute spring and butterfly spring. The plate spring and a spiral spring with large volume and weight, the impact of disturbance degree is small, the energy absorbed per unit volume is small,it can only be installed in the vehicle outside, it is easy to be fire destroyed, although the cylindrical spring can be installed in the car, but it occupies a large space to decorate in the car. Although the disc spring variable stiffness, compact size, easy manufacturing and maintenance, but the single disc load under small deformation, such as the need to use multiple series, and when the load changes, it is easy to cause friction and wear. Several springs in the classical spring style have been eliminated due to the above reasons.

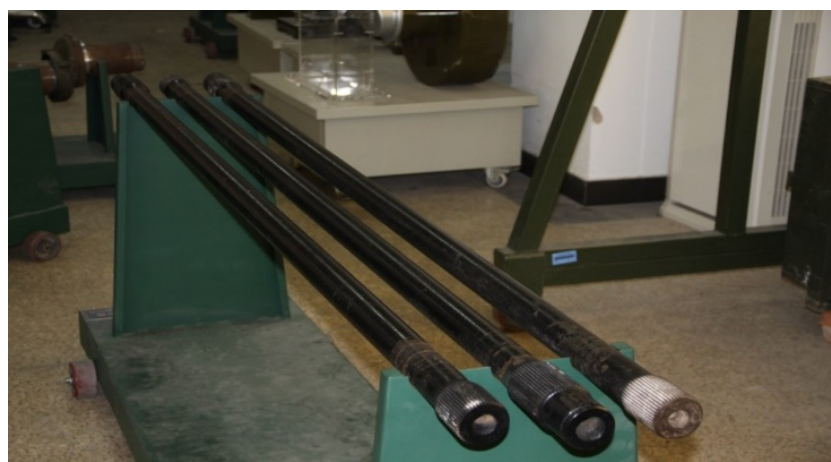

Figure.3 torsion bar spring

The most elastic element used in tracked armored vehicles is the torsion bar spring(see figure 3). It has many advantages, such as simple structure, light weight, small space occupation, mature technology and low cost. Liquid gas spring has good rising characteristics and flexible posture adjustment function, so it has broad prospects for development. The torsion bar spring and the liquid gas spring can satisfy the requirements of the suspension system of the tracked vehicle, match the vehicle running demand under various conditions, and with the continuous improvement of technology, the performance of the elastic components will be mature. 


\subsection{Development of shock absorber.}

A shock absorber is a part of a suspension system that produces damping forces, attenuates vibration, and consumes energy. According to the forming principle of damping force, it can be divided into two kinds: mechanical friction type(see figure 4) and hydraulic type.

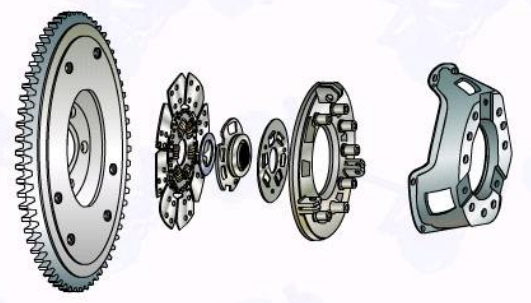

Figure 4. friction damper

Among them, the hydraulic shock absorber can be divided into three types: cylinder, vane and lever piston according to the structure(see figure 5).
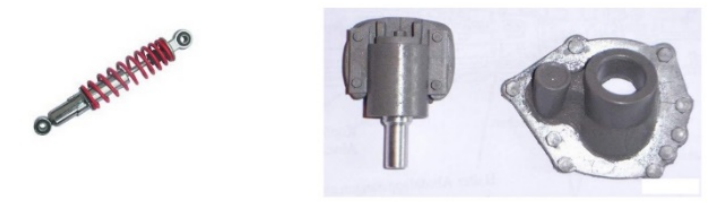

1-Cylinder type hydraulic shock
2-Vane type hydraulic shock

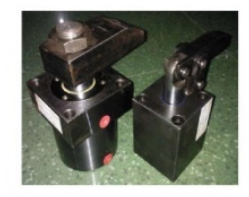

3-Lever piston type hydraulic shock

Figure.5 three types of hydraulic shock absorber

Barrel type hydraulic shock absorber has the advantages of simple structure, light weight, stable performance of damping force and low cost. In 80s the Soviet T-80 tanks, M-46 of America, M-48 M-113 tanks, armored personnel carriers are used in this kind of shock absorber. Compared with the cylinder damper, the vane hydraulic shock absorber has obvious effect on the vibration reduction of the car body, but the damping deviation and temperature decline are greater. The Soviet Union's T-54 and T-72 tanks were using this hydraulic shock absorber. The principle and the shock absorber piston lever type hydraulic damper is similar, stable working performance, but increase the structure of the driving lever to make the complex and increase the weight of the damper .It was used in water tanks of the Soviet union. The mechanical shock absorber is simple in structure, but it has poor wear resistance. With the advent of high temperature and good wear resistance materials, coaxial friction dampers come into being. The German Leopard 2 and the American M1 adopt this kind of shock absorber. Whether the hydraulic shock absorber or mechanical shock absorber, in the actual selection but also pay attention not only to body layout problem considering the damping effect, so as to better improve the suspension performance, so that the vehicle has a good vibration characteristics.

The development of suspension system has experienced the process from passive suspension to semi-active suspension and active suspension. The characteristic parameters of conventional suspension components can not be adjusted in motion, called passive suspension, the passive suspension has the advantages of simple 
structure, reliable use but can not achieve the optimal vibration characteristics under various conditions; the external energy is only used to change the parameters of the suspension elements in the process of running, not directly involved in the work of the suspension system is called semi active suspension, changing device the damping characteristics of hydraulic damper for vibration control of large structure is easy to realize, convergence, and wide attention. Active suspension is an active suspension, and external energy can not only change the suspension characteristic parameters, but also participate in the system work. Active suspension can balance load, speed, traffic conditions and other changes, so as to greatly improve the vibration of car body. A quantitative concept should be used to evaluate the development of vehicle suspension. It is meaningful to study the improvement of suspension only when the body vibration is uncomfortable and the work efficiency is affected. ${ }^{[5]}$.

\section{Research status at home and abroad}

The description of vehicle vibration vehicle suspension model is a vehicle model with two degrees of freedom, simplifies many problems, such as not considering the wheel weight and tire elastic(see figure 6), only on the vertical acceleration and pitching movement of the vehicle.

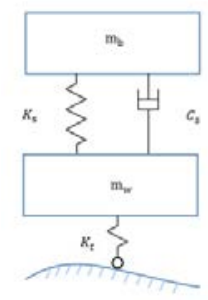

Fig. 6 vehicle two degree of freedom model

Although it was realized that the acceleration of vehicle body was related to comfort, it was only based on subjective experience, and there was no quantitative research. With the continuous improvement of the level of theoretical analysis and the deepening of theoretical research on mathematical physics, solutions to vibration problems with multiple degrees of freedom, such as modal analysis and matrix iteration, have appeared. The reference of state vector, Fourier transform and spectral analysis provides great convenience for vehicle suspension system research. A track vehicle suspension system with non proportional damping characteristics can be accurately calculated by the state vector. Fourier will be able to transform the vibration equation transform of multi degree of freedom vehicle suspension system for transfer between input and output, the input is the road excitation, the transfer function is a function composed of system parameters and frequency. Spectral analysis converts the transitive relation to the relation between input and output power, which can be used to describe vehicle vibration quantitatively. Generally, vehicle suspension has nonlinear characteristics. There are generally two kinds of research methods, one is equivalent linear method and the other is step-by-step integration method. The equivalent linear method is usually calculated in the frequency domain. It is suitable for the vehicle running at medium or low speed. At this point the nonlinear problem of the vehicle is not prominent, and the result is less than the linear 
calculation. The step-by-step integration method can be combined with active vibration control in the time domain.

\section{Conclusions}

At present, there are three aspects of the suspension system, which need further study, nonlinear modeling and control research, vehicle dynamics simulation research and joint control of suspension systems and other chassis systems. With the rapid development of the Internet of things, big data, cloud computing and other information technologies, and the use of unmanned vehicles running on the road, as the "artificial intelligence" of the suspension system is also put forward higher requirements, especially the joint control of suspension system and other system have a wide development and Application prospect.

\section{References}

[1] Xudong Pan, Zhiping Han. Joint operation plan of U.S. Army in 2010[J], Modern defense technology, 1990.

[2] Ming Mao, Yafeng Zhang. Five scientific and technological problems in the running system of high powered tracked vehicles [J]. Beijing: North China Vehicle Research Institute, 2015.

[3]Shuzhen Wang, High speed tracked vehicle driving system [M]. Beijing: Beijing Industrial University Press, 1988

[4] Qingdong Yan, Liandi Zhang, Hui Liu. Tank construction and design [M]. Beijing: Beijing Institute of Technology press, 2006

[5] Faqian Ding. Tracked vehicle suspension system [M]. Beijing: National Defense Industry Press, 2004 